\section{COVID-19 vaccines, hesitancy and mental health}

\author{
Katharine Smith, ${ }^{1,2}$ Sinéad Lambe, ${ }^{1}$ Daniel Freeman, ${ }^{1,2}$ \\ Andrea Cipriani (1) 1,2
}

'None of us will be safe until everyone is safe. Global access to coronavirus vaccines, tests and treatments for everyone who needs them, anywhere, is the only way out'. This statement by $\mathrm{Dr}$ Tedros Adhanom Ghebreyesus, Director-General of the WHO and Ursula von der Leyen, President of the European Commission ${ }^{1}$ has become the rallying call for COVID-19 vaccination. The success of a safe and efficacious COVID-19 vaccine depends just not only on production and availability but also crucially on uptake.

In countries such as the UK where COVID-19 vaccine prioritisation and rollout are proceeding quickly, attitudes to vaccination have rapidly become a priority. ${ }^{2}$ Vaccine hesitancy ('behavioural delay in acceptance or refusal of vaccines despite availability of vaccine services' $)^{3}$ is not a single entity. Reasons vary and there is a continuum from complete acceptance to refusal of all vaccines, with vaccine hesitancy lying between the two poles. Factors involved include confidence (trusting or not the vaccine or provider), complacency (seeing the need or value of a vaccine) and convenience (easy, convenient access to the vaccine). ${ }^{3}{ }^{4}$ Importantly, attitudes to vaccination can change and people who are initially hesitant can still come to see a vaccine's safety, efficacy and necessity. ${ }^{5}$

Developing strategies to address hesitancy is key. ${ }^{6}$ The expedited development and relative novelty of the COVID-19 vaccines have led to public uncertainty. ${ }^{4}$ In addition, efforts to explain the mode of action of these vaccines involve a degree of complexity (eg, immune response and genetic mechanisms), which is difficult to communicate quickly and simply. There are genuine knowledge voids (eg, longterm safety data), which in some cases have been filled with misinformation. ${ }^{7}$ Recent studies have assessed potential acceptance rates specifically for the COVID-19 vaccine. A UK study of more than 5000 adults using a validated scale found $71.7 \%$

\section{${ }^{1}$ Department of Psychiatry, University of Oxford, Oxford, UK \\ ${ }^{2}$ Oxford Health NHS Foundation Trust, Warneford Hospital, Oxford, UK}

Correspondence to Professor Andrea Cipriani, Department of Psychiatry, University of Oxford, Oxford OX3 7JX, UK; andrea.cipriani@psych.ox.ac.uk were willing to be vaccinated, $16.6 \%$ were very unsure and $11.7 \%$ were strongly hesitant, with hesitancy relatively evenly spread across the population. ${ }^{8}$ Willingness to take a vaccine was closely bound to recognition of the collective importance of this decision as well as beliefs about the likelihood of COVID-19 infection, the efficacy, speed of development and side effects of the vaccine. This implies that public information emphasising social benefits may be especially effective, at least in a majority of a population, and information that encourages mistrust or undermines social cohesion will lower vaccine uptake.

We also need to consider more focused strategies about vaccine hesitancy for particular groups, including those groups who are most at risk of hesitancy and severe course of illness. As mental health clinicians, we assessed the impact of mental health conditions on COVID-19 vaccine hesitancy and searched for current guidance in this area using a validated approach. ${ }^{9}$ We found that there is currently no specific guidance in addressing vaccine hesitancy in those with mental health difficulties, ${ }^{10}$ although it is recognised that this is a high-risk group who should be monitored. People with mental health issues, particularly with severe mental illness (SMI), are at particular risk both for infection with COVID-19 and for more severe complications and higher mortality. ${ }^{11}$ Historically, the uptake of similar vaccines such as the influenza vaccine in those with SMI can be as low as $25 \%,{ }^{12}$ and so, similar to other low uptake groups, focused efforts are needed to increase this. Suggestions for change include offering specific discussions from mental health professionals and peer workers, vaccine education and awareness focused for those with SMI, vaccination programmes within mental health services (with coexistent organisational change to facilitate this), alignment with other preventative health strategies (such as influenza vaccination, smoking cessation, metabolic monitoring), focused outreach and monitoring uptake. ${ }^{13}$

Monitoring of vulnerable groups vaccine uptake itself presents problems. In the example of the UK, monitoring of vaccine coverage of most routine immunisation programmes relies on data extracted from primary care systems. To monitor vulnerable groups, the data need to be specifically recorded. For example, Public Health England's national immunisation equity audit in 2019 identified inequalities in uptake by a number of important variables (such as age, geography, ethnicity) but could not assess others including mental illness due to a lack of systematically collected data. ${ }^{14}$ Inequalities that were assessed by the audit were not only in overall coverage but also in timing of vaccines and completion of vaccine schedules. In addition, the extent of a particular inequality varies when it intersects with one or more other factors. In the case of mental illness, multiple long-term conditions across mental and physical health domains as well as socio-economic factors means that both vulnerability and inequality are likely to be additive. ${ }^{11}$ However, vaccine impact may be greater among the most vulnerable despite lower vaccine uptake because the baseline absolute risk is so high. ${ }^{15}$ Therefore, in the context of a COVID-19 vaccine programme, even if vaccine uptake falls short in some high-risk groups, even small increases in vaccine uptake will still have significant health benefits. ${ }^{14}$

Uptake of vaccination is crucial both for the individual and protection of others. It is in everyone's interests to ensure that groups where a low uptake is predicted have extra care and input. At the moment there is little formal guidance on how to support those with mental health issues to access clear and reliable information, and practical and easy access to vaccination for those who are willing. If we are to ensure that 'everyone is safe', we need a concerted and global effort ${ }^{16}$ to guide and focus strategies to support and inform those who are both potentially most hesitant and most vulnerable, including and prioritising those with mental health difficulties.

Twitter Andrea Cipriani @And_Cipriani

Contributors KS and AC drafted the editorial. SL and DF critically revised the manuscript. All authors approved the final version.

Funding $\mathrm{KS}$ and $\mathrm{AC}$ are supported by the National Institute for Health Research (NIHR) Oxford Cognitive Health Clinical Research Facility. AC is also supported by an NIHR Research Professorship (grant RP-2017-08ST2-006), by the NIHR Oxford and Thames Valley Applied Research Collaboration and by the NIHR Oxford Health Biomedical Research Centre (grant BRC-1215-20005). DF is an NIHR Senior Investigator. The views expressed are those of the authors and not necessarily those of the UK National Health Service, the NIHR or the UK Department of Health. 
Competing interests $\mathrm{AC}$ has received research and consultancy fees from INCiPiT (Italian Network for Paediatric Trials), CARIPLO Foundation and Angelini Pharma, outside the submitted work. KS, SL and DF have nothing to declare.

Patient consent for publication Not required.

Provenance and peer review Not commissioned; internally peer reviewed.

This article is made freely available for use in accordance with BMJ's website terms and conditions for the duration of the covid-19 pandemic or until otherwise determined by BMJ. You may use, download and print the article for any lawful, non-commercial purpose (including text and data mining) provided that all copyright notices and trade marks are retained.

(c) Author(s) (or their employer(s)) 2021. No commercial re-use. See rights and permissions. Published by BMJ.

\section{A) Check for updates}

To cite Smith K, Lambe S, Freeman D, et al. Evid Based Ment Health 2021;24:47-48.

Received 29 March 2021

Accepted 31 March 2021

Published Online First 13 April 2021

Evid Based Ment Health 2021;24:47-48.

doi:10.1136/ebmental-2021-300266

ORCID iD

Andrea Cipriani http://orcid.org/0000-0001-5179-8321

\section{REFERENCES}

1 WHO. A global pandemic requires a world effort to end it - none of US will be safe until everyone is safe. Available: https://www.who.int/news-room/ commentaries/detail/a-global-pandemic-requires-aworld-effort-to-end-it-none-of-us-will-be-safe-untileveryone-is-safe [Accessed 23 Mar 2021].

2 Osama T, Majeed A. How can we address covid-19 vaccine hesitancy and improve vaccine acceptance? The BMJ Opinion 2021 https://blogs.bmj.com/bmj/ 2021/02/19/how-can-we-address-covid-19-vaccinehesitancy-and-improve-vaccine-acceptance/

3 SAGE. (strategic Advisory group of experts on immunization). Report of the SAGE Working group on vaccine hesitancy. Available: https://www.who.int immunization/sage/meetings/2014/october/1_Report_ WORKING GROUP vaccine hesitancy final.pdf [Accessed 1 Oct 2014].

4 Social science in humanitarian action platform. Rapid review: vaccine Hesitancy and building confidence in COVID-19 vaccination, 2020. Available: https://www. socialscienceinaction.org/resources/rapid-review vaccine-hesitancy-and-building-confidence-in-covid19-vaccination/

5 The Royal Society and the British Academy. COVID-19 vaccine deployment: behaviour, ethics, misinformation and policy strategies, 2020. Available: https:// royalsociety.org/-/media/policy/projects/set-c/set-cvaccine-deployment.pdf?la=en-GB\&hash $=43073 \mathrm{E} 54$ 29C87FD2674201CA19280A8E

6 Razai MS, Osama T, McKechnie DGJ, et al. Covid-19 vaccine hesitancy among ethnic minority groups. $B M J$ 2021;372:n513.

7 Horton R. Offline: managing the COVID-19 vaccine infodemic. Lancet 2020:396:1474.

8 Freeman D, Loe BS, Chadwick A, et al. COVID-19 vaccine hesitancy in the UK: the Oxford coronavirus explanations, attitudes, and narratives survey (Oceans) II. Psychol Med 2020;11:1-15.

9 Smith K, Ostinelli E, Cipriani A. Covid-19 and mental health: a transformational opportunity to apply an evidence-based approach to clinical practice and research. Evid Based Ment Health 2020:23:45-6.

10 Oxford Precision Psychiatry Lab (NIHR Oxford Health Biomedical Research (entre). Vaccine uptake and vaccine hesitancy. Available: https://oxfordhealthbrc. nihr.ac.uk/our-work/oxppl/vaccine-uptake-and-vaccinehesitancy/ [Accessed 23 Mar 2021].

11 Cipriani A, Smith K, Macdonald O. Covid-19 vaccination programme: where do people with mental health difficulties lie within the order of priority? The BMJ Opinion 2021 https://blogs.bmj.com/bmj/2021/ 02/16/covid-19-vaccination-programme-where-dopeople-with-mental-health-difficulties-lie-within-theorder-of-priority/

12 Lorenz RA, Norris MM, Norton LC, et al. Factors associated with influenza vaccination decisions among patients with mental illness. Int J Psychiatry Med 2013;46:1-13.

13 Warren N, Kisely S, Siskind D. Maximizing the uptake of a COVID-19 vaccine in people with severe mental illness: a public health priority. JAMA Psychiatry 2020 doi:10.1001/jamapsychiatry.2020.4396. [Epub ahead of print: 15 Dec 2020]

14 Public Health England. Independent report. Annex A: COVID-19 vaccine and health inequalities: considerations for prioritisation and implementation, 2021. Available: https://www.gov.uk/government/ publications/priority-groups-for-coronavirus-covid-19vaccination-advice-from-the-jcvi-30-december-2020/ annex-a-covid-19-vaccine-and-health-inequalities considerations-for-prioritisation-and-implementation [Accessed 6 Jan 2021].

15 Hungerford D, Vivancos R, Read JM, et al. Rotavirus vaccine impact and socioeconomic deprivation: an interrupted time-series analysis of gastrointestinal disease outcomes across primary and secondary care in the UK. BMC Med 2018:16:10

16 Horton R. Offline: the lessons of smallpox eradication for COVID-19. Lancet 2021:396:1951. 